\title{
Preparation and Electrochemical Performances of Cellulose Nanofiber/Graphene Nanosheet/Polyaniline Composite Film via in-Situ Polymerization
}

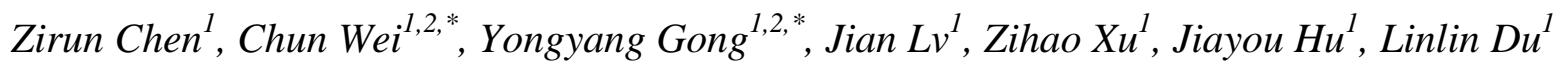 \\ ${ }^{1}$ College of Materials Science and Engineering, Guilin University of Technology, Guilin 541004, P. R. \\ China \\ ${ }^{2}$ Key Laboratory of New Processing Technology for Nonferrous Metals and Materials, Ministry of \\ Education \\ *E-mail: 1986024@glut.edu.cn, yygong@glut.edu.cn
}

doi: $10.20964 / 2017.07 .61$

Received: 18 April 2017 / Accepted: 12 May 2017 / Published: 12 June 2017

This study demonstrates that green and renewable cellulose nanofiber can be applied in the production of electrode materials for energy-storage supercapacitors. We prepared cellulose nanofiber/graphene nanosheet/polyaniline (CGP) composite films through in-situ polymerization and vacuum filtration and studied the effect of aniline amounts on the electrochemical properties of CGP films. The composite films were characterized using FT-IR, XRD, XPS, Raman, SEM, and EDX, and the results show that their specific capacitance initially increased and then decreased as the amount of aniline increased. Among the films studied, the $\mathrm{CGP}_{1: 15}(1: 15$ is the mass ratio of GNS to aniline in the feedstock)films achieved a specific capacitance of $430.78 \mathrm{~F} / \mathrm{g}$ at a current density of $1 \mathrm{~A} / \mathrm{g}$ and a charge transfer resistance of $1.65 \Omega$. After 1000 charge-discharge cycles, $79.33 \%$ of the specific capacitance was maintained at $5 \mathrm{~A} / \mathrm{g}$.

Keywords: cellulose nanofiber, graphene nanosheet, polyaniline, electrochemical performance

\section{$\underline{\text { FULL TEXT }}$}

(C) 2017 The Authors. Published by ESG (www.electrochemsci.org). This article is an open access article distributed under the terms and conditions of the Creative Commons Attribution license (http://creativecommons.org/licenses/by/4.0/). 